\title{
Back to basics: a non-photorealistic rendering method for the analysis of texts from 3D Roman inscriptions
}

Miguel Carrero-Pazos ${ }^{1, *} \&$ David Espinosa-Espinosa ${ }^{1}$

This paper presents the results of a non-photorealistic rendering approach to analysing Roman inscriptions, which uses line drawings to highlight the text of two epigraphs from Galicia in north-west Spain.

\section{Introduction and recording process}

Current approaches in Roman epigraphy include using 3D modelling techniques to record artefacts and share the data online. Although the full potential of 3D modelling for such tasks has yet to be realised, methods such as shape from shading, reflectance transformation imaging or the exaggerated shading technique have been applied to enhance inscriptions virtually, in order to provide better clarity for epigraphic texts (e.g. Rusinkiewicz et al. 2006; Earl et al. 2010).

We propose the application of non-photorealistic rendering (NPR) techniques to extract text information from 3D models of Roman inscriptions, using line drawings to represent $3 \mathrm{D}$ shapes. Two inscriptions from Galicia in north-west Spain are considered here. The first is a votive altar from Viloira (Rodríguez Colmenero 1997: n 130) (Figure 1: A); the second, a hospitality tabula from Castromao (Rodríguez Colmenero 1997: n⿳ 610) (Figure 1: B). Structure from motion photogrammetry was used to create the $3 \mathrm{D}$ models (following Verhoeven 2011; Agisoft 2012). Photographs were taken using a Canon EOS 1200D reflex camera, and the 3D models were created with the commercial software Agisoft Photoscan.

\section{Line drawings for automatic extract text information}

The use of multiple line drawings such as edges, silhouettes or contours to bring geometry and shading in scenes or objects are techniques widely used in art. While artists may utilise their visual perception and experience to make their own decisions concerning which lines are relevant for indicating expressiveness, we employ computer-generated line-drawing techniques to produce effective drawings through mathematical algorithms (Rusinkiewicz et al. 2008). Some of them are well known, such as the canny edge detector, already applied for archaeological purposes; rock art engravings, for example (Díaz-Andreu et al. 2006).

We used real-time suggestive contours (RTSC) software (http://gfx.cs.princeton.edu/ proj/sugcon/) to generate automatic drawing lines over 3D models. This software includes

1 University of Santiago de Compostela, Department of History, Faculty of Geography and History, Praza da Universidade 1, 15782 Santiago de Compostela, Spain

* Author for correspondence (Email:miguel.carrero.pazos@gmail.com)

(c) Antiquity Publications Ltd, 2018 ANTIQUiTY 92 364, e7 (2018): 1-7 

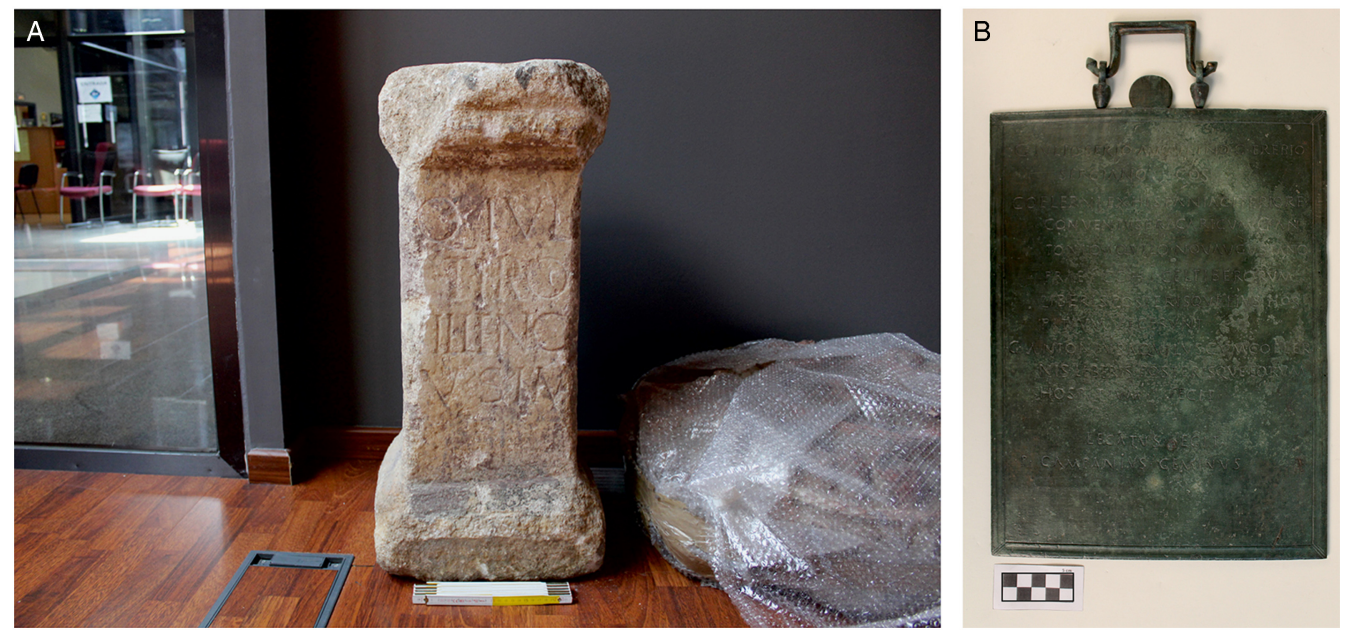

Figure 1. A) Viloira's votive altar; B) Castromao tabula. Photographs by the authors.

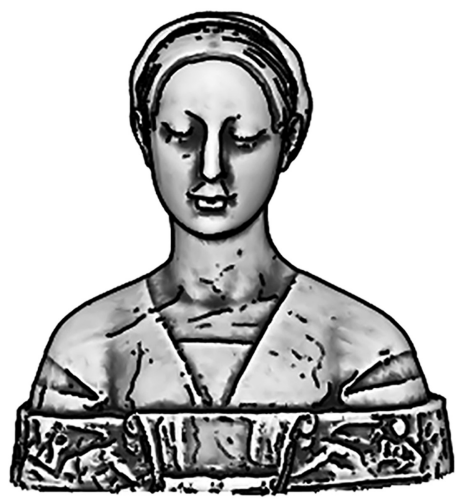

\begin{tabular}{|c|c|c|c|c|c|}
\hline \multicolumn{6}{|l|}{ Options } \\
\hline Lines: & \multirow{2}{*}{$\begin{array}{l}\text { Line tests: } \\
\square \text { Draw hidden lines } \\
\sqrt{\nabla} \text { Trim "inside" contours }\end{array}$} & \multirow{4}{*}{$\begin{array}{l}\text { Line style: } \\
\square \text { Texture mapping } \\
\bar{v} \text { Fade lines } \\
\square \text { Draw in color } \\
\square \text { Hermite interp }\end{array}$} & \multirow{6}{*}{$\begin{array}{l}\text { Lighting: } \\
\text { O None } \\
\text { O Lambertian } \\
6 \text { Lambertian2 } \\
\text { O Hemisphere } \\
\text { Toon (grayswhite) } \\
\text { Toon (blackwhite) } \\
\text { Gooch }\end{array}$} & \multirow{5}{*}{$\begin{array}{l}\text { Vectors: } \\
\square \text { Normal } \\
\square \text { Principal } 1 \\
\square \text { Principal } 2 \\
\Gamma \text { Asymptotic } \\
\square \text { Proj. View }\end{array}$} & Smooth Mesh \\
\hline $\begin{array}{l}\text { Exterior silhouette } \\
\sqrt{\nabla} \text { Occluding contours }\end{array}$ & & & & & Smooth Normals \\
\hline V Suggestive contours & $\bar{\nabla}$ Trim SC & & & & Smooth Curv \\
\hline $\begin{array}{l}\square \text { Suggestive hlt. } \\
\text { Principal hlt. (R) }\end{array}$ & [SC thresh- & & & & Smooth DCurv \\
\hline D Principal hit. (V) & {$[\ulcorner]$} & Mesh style: & & & Subdivide Mesh \\
\hline$\square$ Ridges & V Trim SH & C White & & Camera: & Screencap \\
\hline Dapparent ridges & $=$ & C Curvature (color) & & Lual viewport & Exit \\
\hline 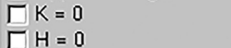 & V Trim PH & (- Curvature (gray) & & & \\
\hline $\begin{array}{l}\text { DwKr }=\text { thresh. } \\
\text { Boundaries }\end{array}$ & {$\left[\begin{array}{ll}\mathrm{PH} \text { thresh } & 0.04 \\
& =\end{array}\right.$} & $\square$ Draw edges & $\begin{array}{l}\text { Direction } \\
\nabla \text { On camera }\end{array}$ & & \\
\hline$\square$ Isophotes & V Trim RV & & & & \\
\hline \# Isophotes |20 & RV thresh & & & & \\
\hline Г Topo lines & $=1$ & & & & \\
\hline \# Topo lines 20 & V Trim AR & & & & \\
\hline$\left\lceil\begin{array}{ll}\text { Topo oftset } & 0 \\
& \end{array}\right.$ & {$\left[\begin{array}{ll}\text { AR thresh- } & 0.1 \\
\Longleftarrow\end{array}\right]$} & & & & \\
\hline
\end{tabular}

Figure 2. 3D model of Laurana's bust, produced using real-time suggestive contours (RTSC) software, showing suggestive and occluding contours.

(C) Antiquity Publications Ltd, 2018 
A

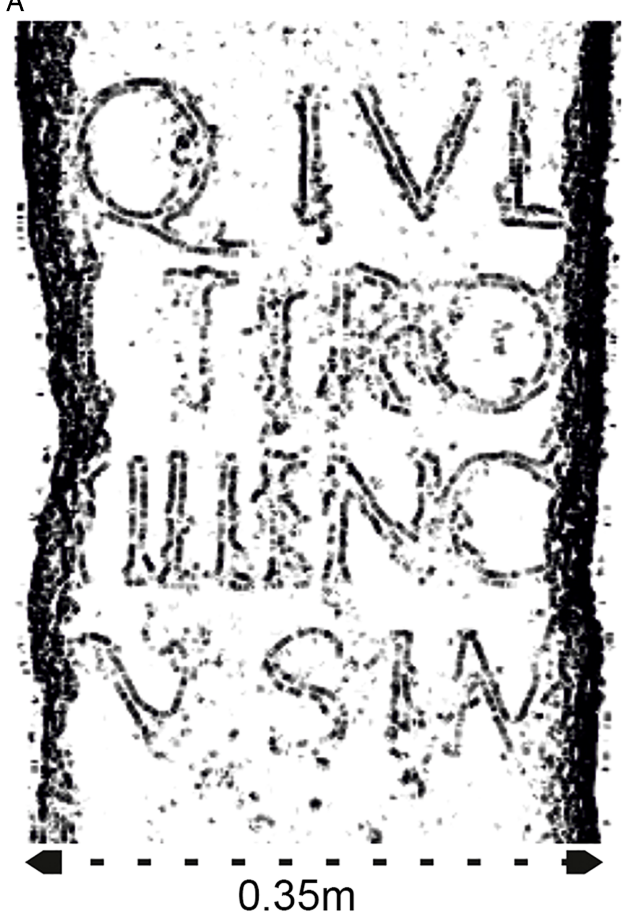

B

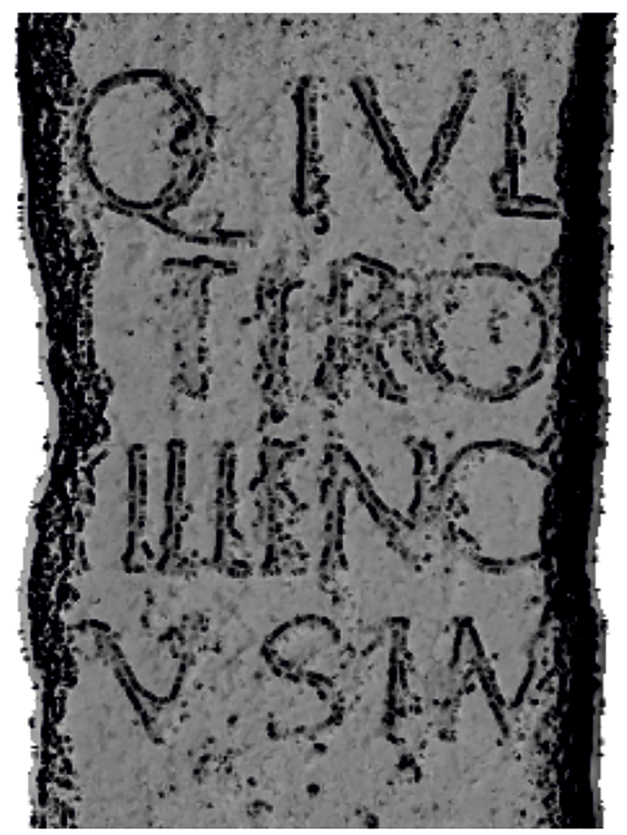

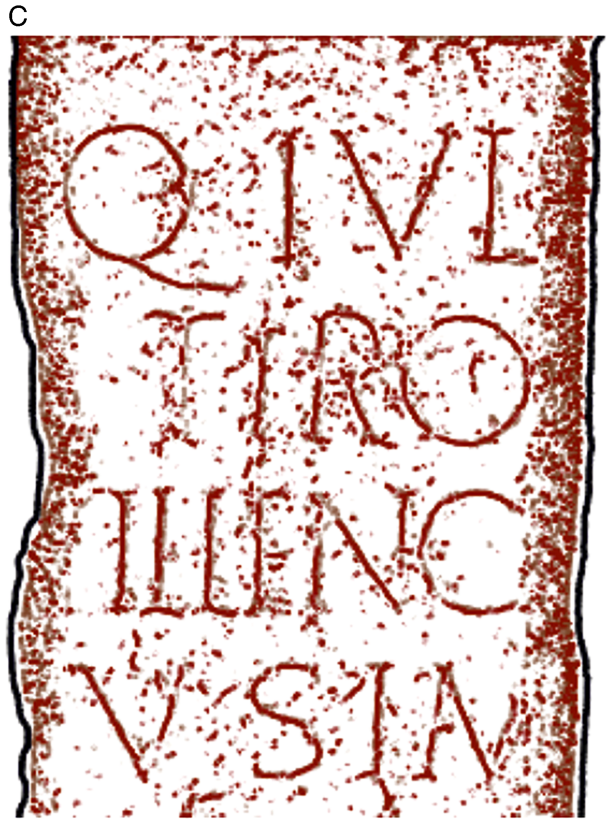

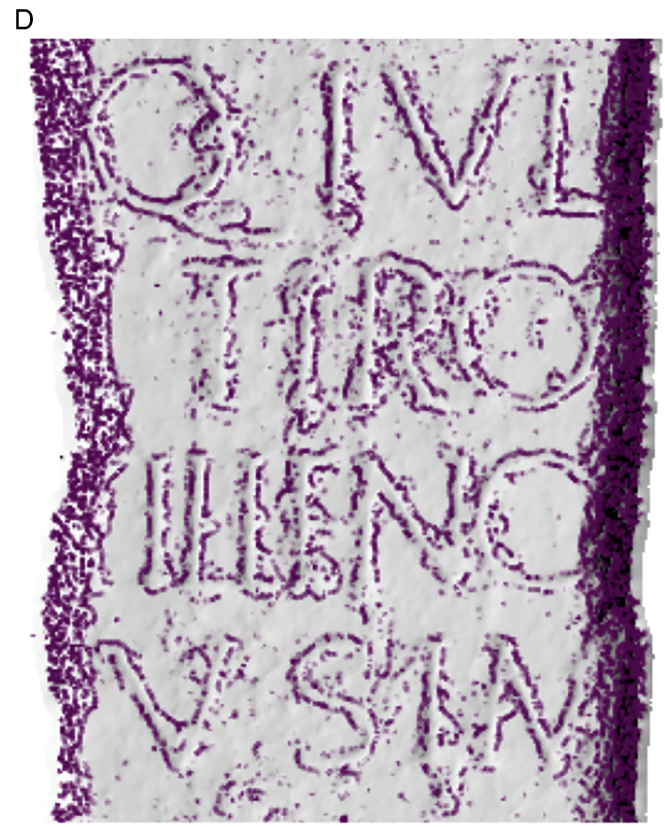

Figure 3. Viloira's 3D model with different line drawing types: A) occluding contours and suggestive contours; B) occluding contours and suggestive contours, with the mesh coloured by curvature (grey) and Lambertian lighting; C) principal highlights and valleys; D) ridges. Images extracted from RTSC software. 

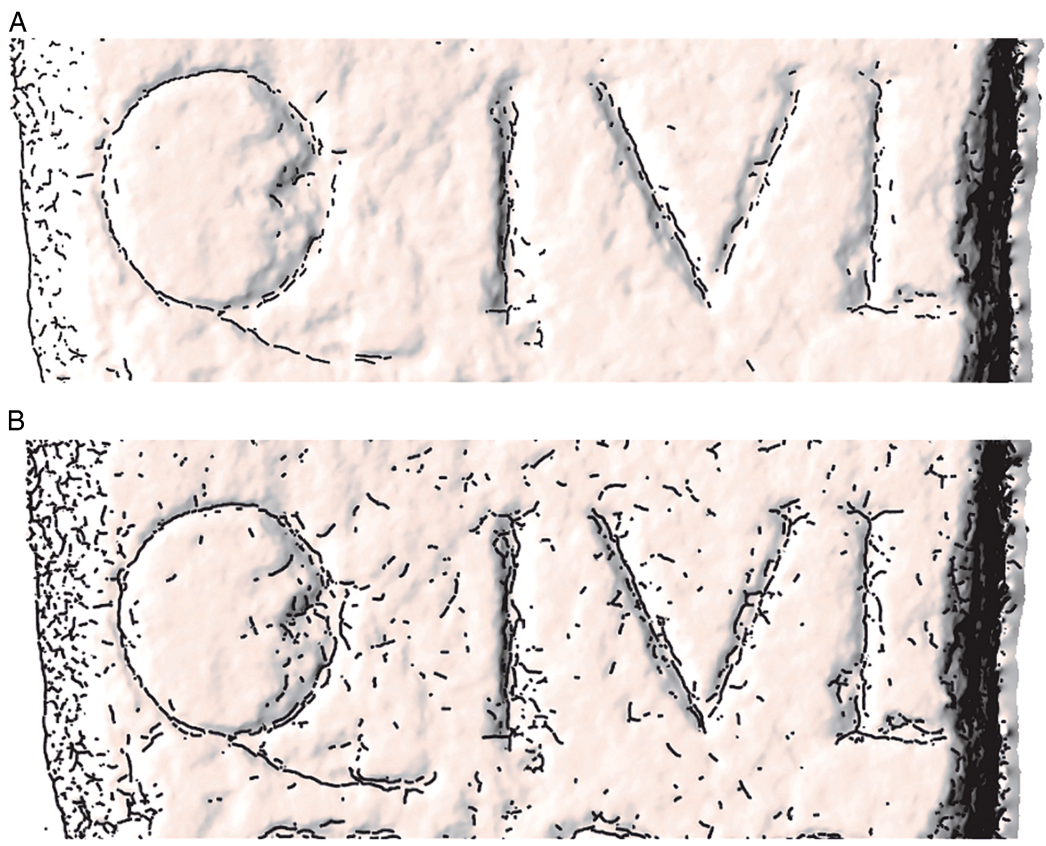

C

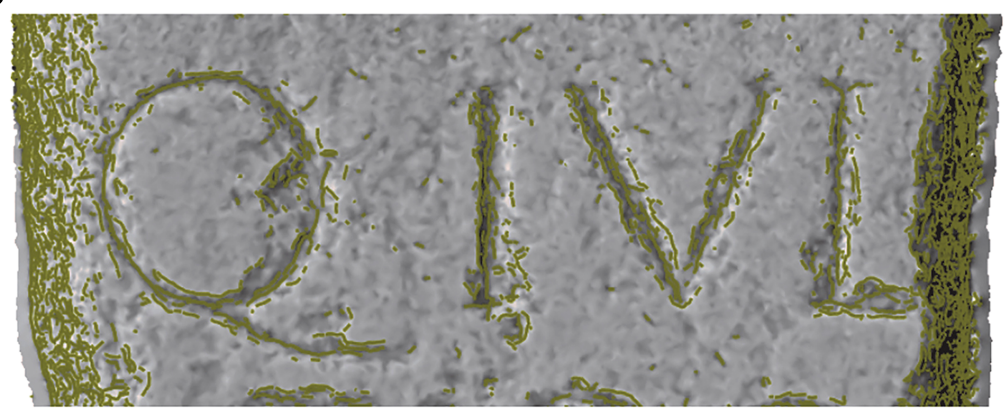

D

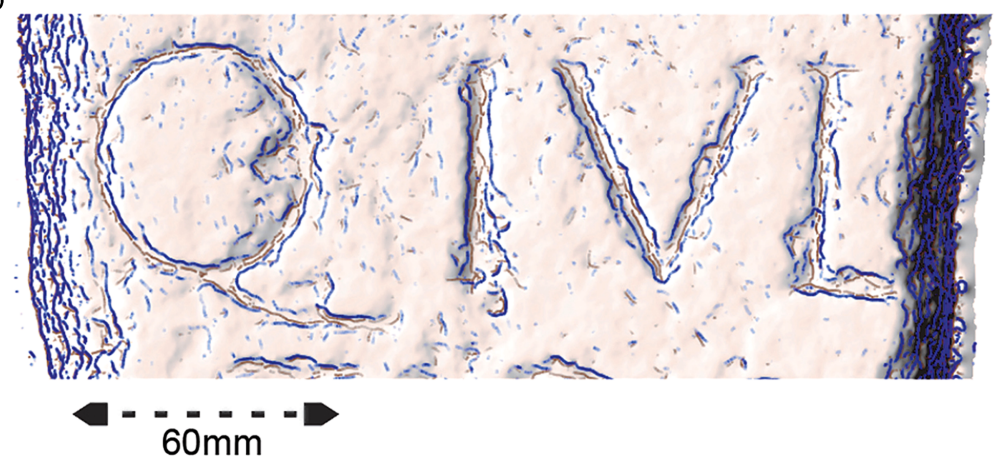

Figure 4. Detail of the text Q(uintus) Iul(ius): A) valleys (threshold: 0.161); B) valleys (threshold: 0.0848); C) apparent ridges (threshold: 0.0179); D) suggestive contours (threshold: 0.00536) and valleys (threshold: 0.0714). Images extracted from RTSC software.

(C) Antiquity Publications Ltd, 2018 
algorithms to compute drawing lines, such as occluding and suggestive contours, suggestive and principal highlights, ridges, valleys and apparent ridges, among other functions (DeCarlo et al. 2003; DeCarlo \& Rusinkiewicz 2007; Judd et al. 2007) (Figure 2).

Application of line drawings over the Viloira altar's 3D model shows that different lines can be employed to extract the epigraphic text of the inscription (Figure 3). We first applied a digital smoothing tool to the 3D model to eliminate the microsurface details, preserving both occluding and suggestive contours to enhance the letters (Figure 3: A). The text can be more clearly depicted by using the curvature (grey) and the Lambertian lighting, as shown in Figure 3 (B). Principal highlights (threshold: 0.00179) and valleys (threshold: 0.0804) (Figure 3: C), or only the ridges (threshold: 0.625) (Figure 3: D), can also be applied.

A critical aspect of the procedure is the delineation of the threshold, the value modifying the extent to which lines are drawn, so it changes the results. Figure 4 shows how the threshold affects the line drawing creation, centred on the first line 'Q(uintus) Iul(ius)'. In Figure $4(\mathrm{~A}-\mathrm{B})$, valleys are represented with different threshold values that modified how lines convey the letter shapes. The lower the threshold, the more noise was introduced, although the letters were better defined. The application of apparent ridges (Figure 4: C)another type of contour-seems to enhance the letters, although better results were obtained by combining suggestive contours (blue) and valleys (brown) (Figure 4: D).

Analysis of the Castromao tabula provides clearer results. The use of only valley lines highlights the inscribed text, the threshold level once again proving critical (Figure 5). Although a high threshold eliminates much of the noise, some letters are not visible (Figure 5: A). Reducing the threshold value (Figure 5: B) makes the whole text readable, but generates more noise. This is also apparent in Figure 6, which focuses on the top of the plaque.
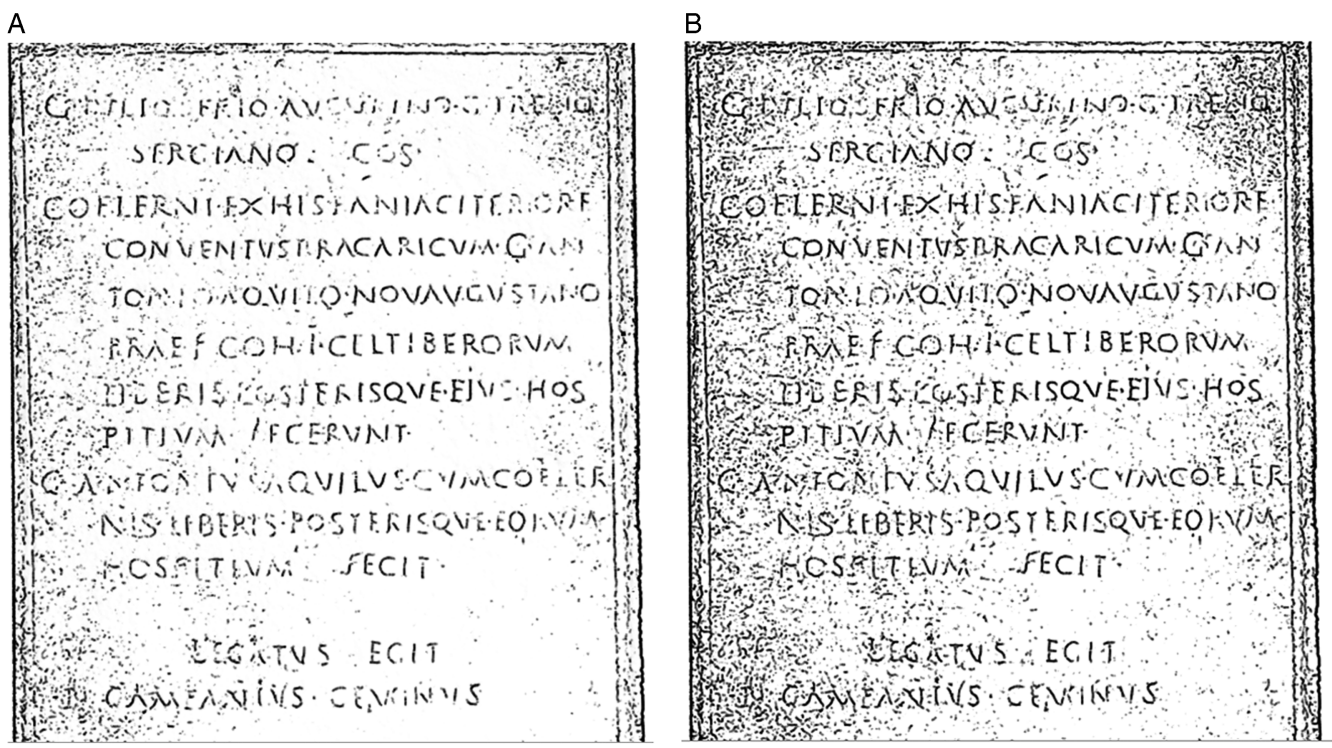

\section{$0.23 \mathrm{~m}$}

Figure 5. Valley lines of Castromao tabula: A) threshold: 0.272; B) threshold: 0.17. Images extracted from RTSC software. 


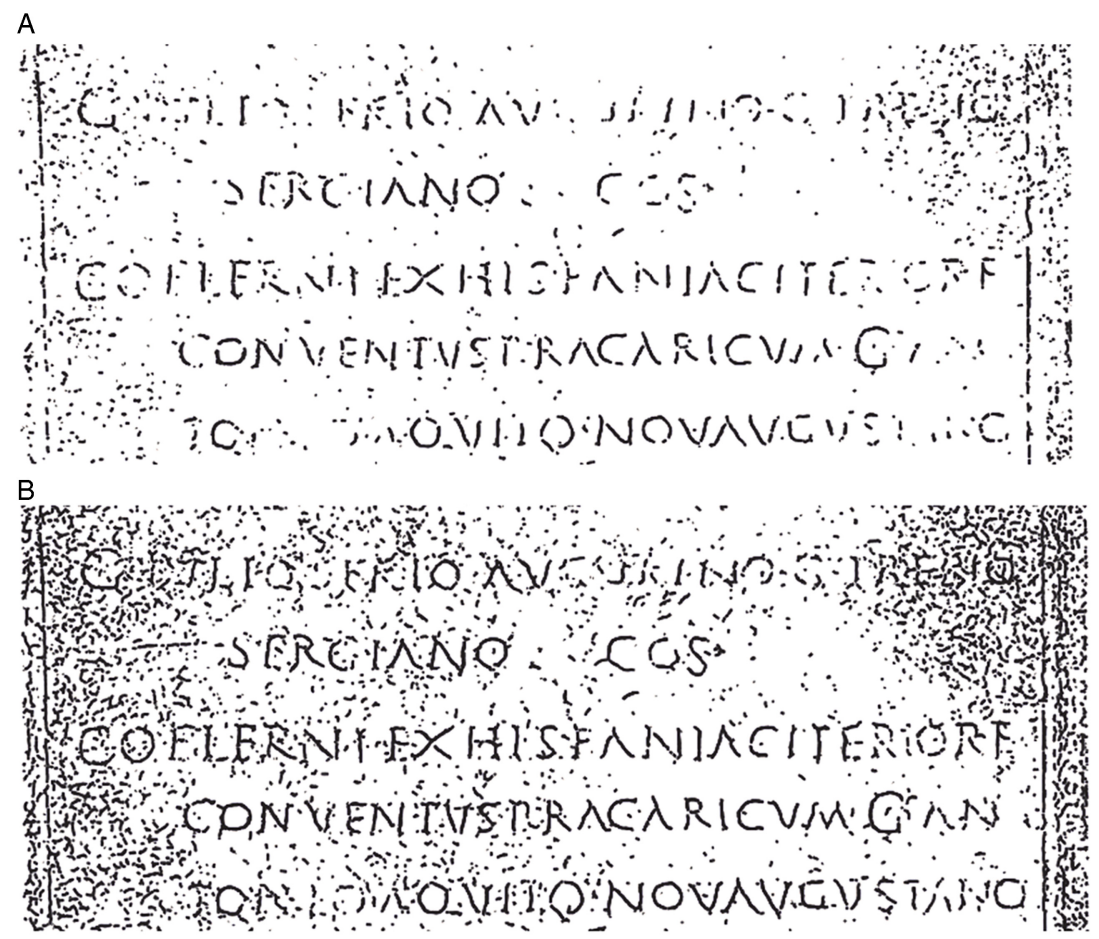

C

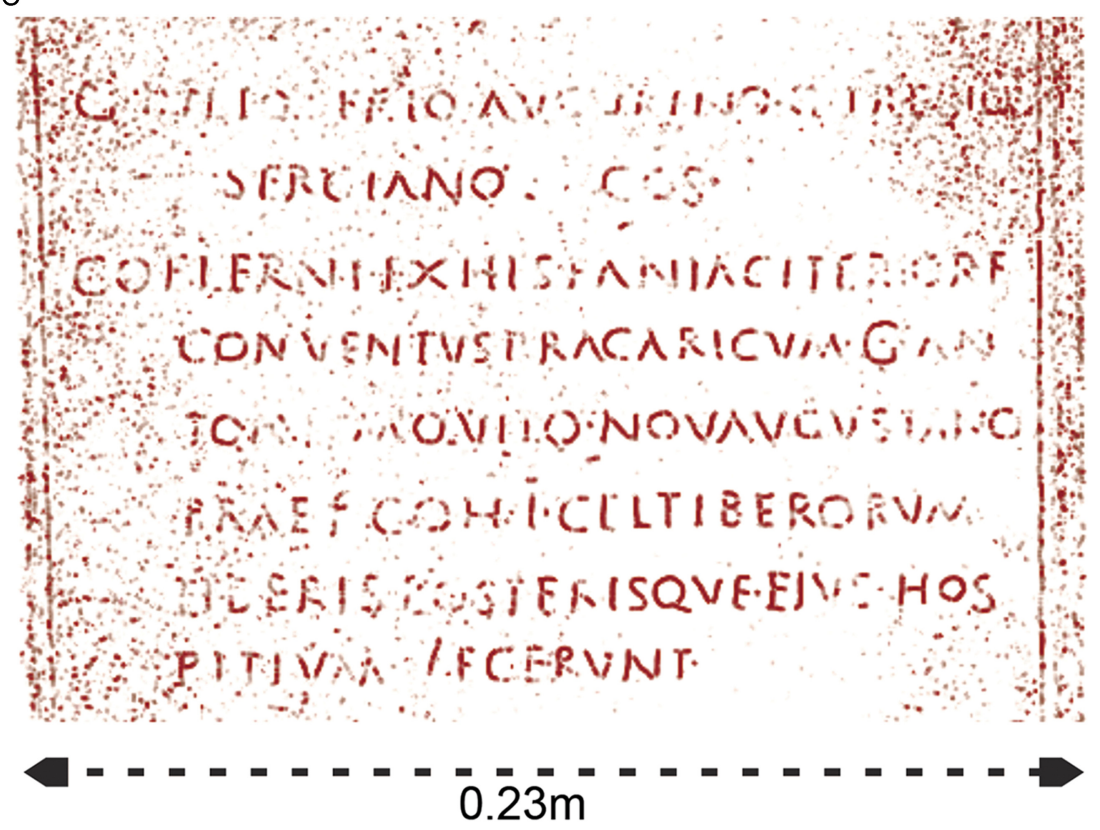

Figure 6. Detail of the first lines of the Castromao tabula, using principal highlights and valleys to enhance the letters: A) principal highlights threshold: 0.0268; valley threshold: 0.29; B) principal highlights threshold: 0.0268; valley threshold: 0.129 ; C) coloured version: principal highlights threshold: 0.0268 ; valley threshold: 0.129 . Images extracted from RTSC software.

(C) Antiquity Publications Ltd, 2018 
A combined approach with principal highlights and valleys is the best way to visualise the letters, although, again, the threshold influences the results strongly (cf. Figure 6: A-B). The colour version is recommended for better results (Figure 6: C).

\section{Conclusions}

We propose the application of new techniques to study the surface of 3D epigraphic models. A combination of different line types seems the most useful approach in highlighting textual information, although high noise results when applying this to extremely deteriorated inscriptions. It is necessary to use NPR approaches to complement traditional and computeraided epigraphic methods.

\section{Acknowledgements}

The authors thank the Council of O Barco de Valdeorras and the Archaeological Museum of Ourense for the access to the inscriptions. The 3D model of Laurana's bust was obtained from MeshLab (http://meshlab. sourceforge.net).

\section{References}

Agisoft, llc. 2012. Agisoft PhotoScan user manual: professional edition (version 1.2). Moscow: Agisoft LLC.

DeCarlo, D. \& S. Rusinkiewicz. 2007. Highlight lines for conveying shape, in B. Gooch (ed.) NPAR '07 Proceedings of the $5^{\text {th }}$ International Symposium on Non-photorealistic Animation and Rendering (San Diego, California, August 04-05/ 2007): 63-70. New York: Association for Computing Machinery.

DeCarlo, D., A. Finkelstein, S. Rusinkiewicz \& A. Santella. 2003. Suggestive contours for conveying shape. ACM Transactions on Graphics 22: 848-55.

Díaz-Andreu, M., C. Brooke, M. Rainsbury \& N. Rosser. 2006. The spiral that vanished: the application of non-contact recording techniques to an elusive rock art motif at Castlerigg stone circle in Cumbria. Journal of Archaeological Science 33: 1580-87. https://doi.org/10.1016/j.jas.2006.02.010

Earl, G., G. Beale, K. Martínez \& H. Pagi. 2010. Polynomial texture mapping and related imaging technologies for the recording, analysis and presentation of archaeological materials.
International Archives of Photogrammetry, Remote Sensing and Spatial Information Science 38: 21823.

Judd, T., F. Durand \& E. Adelson. 2007. Apparent ridges for line drawing. ACM Transactions on Graphics 26(3): article no. 19. https://doi.org/10.1145/1275808. 1276401

Rodríguez Colmenero, A. 1997. Aquae Flaviae: I. Fontes epigráficas da Gallaecia meridional interior. Chaves: Câmara Municipal de Chaves.

Rusinkiewicz, S., M. Burns \& D. DeCarlo. 2006. Exaggerated shading for depicting shape and detail. ACM Transactions on Graphics 25: 1199-205. https://doi.org/ 10.1145/1141911.1142015

Rusinkiewicz, S., F. Cole, D. DeCarlo \& A. Finkelstein. 2008. Line drawings from 3D models. SIGGRAPH 2008 class. Available at: http://gfx.cs.princeton.edu/proj/sg08lines/ (accessed 7 August 2018).

Verhoeven, G. 2011. Taking computer vision aloft-archaeological three-dimensional reconstructions from aerial photographs with Photoscan. Archaeological Prospection 18: 67-73. https://doi.org/10.1002/arp.399 